\title{
Behavioral antecedents for handwashing in a low-income urban setting in Bangladesh: an exploratory study
}

\author{
Musarrat J. Rahman ${ }^{1 *}$, Fosiul A. Nizame1, Leanne Unicomb ${ }^{1}$, Stephen P. Luby ${ }^{2}$ and Peter J. Winch ${ }^{3}$
}

\begin{abstract}
Background: Health programs commonly promote handwashing by drawing attention to potential fecal contamination in the environment. The underlying assumption is that the thought of fecal contamination will result in disgust, and motivate people to wash their hands with soap. However, this has not proven sufficient to achieve high rates of handwashing with soap at key times. We argue that handwashing with soap is influenced by broader range of antecedents, many unrelated to fecal contamination, that indicate to people when and where to wash their hands. This exploratory study aimed to identify and characterize this broader range of handwashing antecedents for use in future handwashing promotion efforts.

Methods: First, an initial list of behavioral antecedents was elicited through unstructured interviews, focus group discussions and observation with residents, from a low-income community in Dhaka, Bangladesh, who were also recipients of a handwashing intervention. Then, photographs representing three categories of behavioral antecedents were taken: activities of daily living, visual or tactile sensations, and handwashing-related hardware and activities. Finally, the research team conducted ranking exercises with a new set of participants, from the same area, to assess the perceived importance of each antecedent illustrated by the photographs. The research team probed about perceptions regarding how and why that particular antecedent, represented by the photograph, influences handwashing behavior.
\end{abstract}

Results: After coming out of the bathroom and dirt (moyla) on hands were the two antecedents that ranked highest. In all the categories, intervention-related antecedents (three key times for handwashing which included handwashing after coming out of the bathroom, after cleaning a child's anus and before food preparation; intervention provided items that included handwashing station, soapy water bottle, handwashing reminders from posters and community health provider visits) that were being promoted actively in this community were perceived favorably in the qualitative responses, but did not consistently rank higher than non-intervention items. However, many other antecedents were reported to influence when and where people wash their hands: cutting greasy fish, starting a meal, contact with oil and fat stuck to dishes, oil and lice from hair, sweat, unwashed vegetables, reminders from son and daughter or observing others wash hands, and observing the sunset.

Conclusions: Beyond well-recognized antecedents related to fecal contact and dirt on hands, we identified a broader set of antecedents not reported in the literature. Adopting a handwashing promotional strategy to highlight existing antecedents that people themselves have identified as important can help inform the content of an intervention that is more relatable and effective in increasing handwashing practices.

Keywords: Handwashing, Antecedent, Handwashing habit, Handwashing promotion, Health promotion, Behavior change

\footnotetext{
* Correspondence: rahman.musarrat@gmail.com

'International Center for Diarrheal Diseases Research, Bangladesh (icddr,b),

Dhaka, Bangladesh

Full list of author information is available at the end of the article
}

(c) The Author(s). 2017 Open Access This article is distributed under the terms of the Creative Commons Attribution 4.0 International License (http://creativecommons.org/licenses/by/4.0/), which permits unrestricted use, distribution, and reproduction in any medium, provided you give appropriate credit to the original author(s) and the source, provide a link to the Creative Commons license, and indicate if changes were made. The Creative Commons Public Domain Dedication waiver (http://creativecommons.org/publicdomain/zero/1.0/) applies to the data made available in this article, unless otherwise stated. 


\section{Background}

Diarrhea-related diseases and pneumonia contribute significantly to mortality of children under five globally [1] and in Bangladesh [2]. Handwashing promotion can reduce the risk of both diarrhea [3] and respiratory infections $[4,5]$. Specifically, handwashing can reduce diarrhea incidence by an approximate $30 \%$ - 48\% ([3, 6]. Handwashing also can help control epidemics such as cholera and dysentery in urban slums [7] and refugee camps [8], reducing neonatal $[9,10]$ and maternal infections [11] and controlling pandemic influenza [12]. However, rates of handwashing are low in low-income countries [13]. While handwashing promotion interventions have demonstrated efficacy, handwashing behavior may not be sustained over time [14].

To be effective in achieving health outcomes, handwashing must be practiced at key times that include after stool contact, and before contact with food and water [13, 15]. There has been relatively little study of how specific intervention activities or other factors contribute to handwashing at key times $[13,15,16]$, although there is considerable evidence globally that handwashing after fecal contact is not commonly practiced [13]. In a nationally-representative sample of Kenyan households, respondents were asked about their level of agreement with a number of statements on factors affecting handwashing. Agreement that handwashing is habitual was the variable most strongly associated with handwashing with soap, as measured by direct observation of handwashing in households included in the survey [17]. Arguably, handwashing with soap at key times and habitual handwashing more generally are influenced by features of the environment that act as signals, telling people when and where to wash their hands. Researchers refer to these features of the environment with a variety of terms: antecedent [18], trigger, cue [19-21] and stimulus [18].

In this paper, we adopt the term antecedent to refer to these features of the environment, and apply the framework of Applied Behavior Analysis- "the process of systematically applying interventions based upon principles of learning theory to improve socially significant behaviors to a meaningful degree, and to demonstrate that the interventions are responsible for improvement in behavior" [22]. Applied Behavioral Analysis has been used to identify and analyze antecedents and consequences of pro-environmental behaviors, and planning appropriate interventions [23]. The current study applies this methodology to study the relationship between handwashing behaviors and the environment. We contend that understanding antecedents of handwashing may open up new ways to promote handwashing at key times, by building upon or modifying existing antecedents.

For the purposes of this paper, we consider the term antecedent as synonymous with "antecedent environmental stimulus" [18] and we also consider the term handwashing to refer to any type of hand rinsing, with or without soap. Washing hands with water is common in the community from where the data for the current study was collected $[24,25]$. While washing hands with soap has optimal health benefits, washing hands with water only is more beneficial than not washing hands at all [24]. We define a handwashing antecedent as a feature of the environment that 1) occurs prior to the person performing handwashing and 2) prompts a person to wash hands immediately (if the person is in a location where handwashing can be performed), or after developing the intention to wash hands.

In previous interventions that promoted handwashing by eliciting feelings of disgust, the underlying assumption was that seeing, smelling or thinking about fecal material induces disgust, thereby stimulating handwashing at key times [26-33]. Relatively little attention has been devoted to identifying antecedents of handwashing that are not related to feces or inducing feelings of disgust [34].

\section{Methods}

Aim

We sought to develop a comprehensive list of behavior antecedents for handwashing as a basis for future research on how to promote consistent handwashing. Our primary objective in this exploratory study was to elicit an initial list of behavioral antecedents from the community participants. Our secondary objective was to assess the perceived importance of each of these antecedents that were previously identified by community participants.

\section{Study setting}

This study was conducted in the low-income Bauniabad neighborhood, Mirpur subdistrict in Dhaka City. The site was within one of three study arms (the vaccine and behavior change arm vaccine) in a randomized controlled trial named "Introduction of Cholera Vaccine in Bangladesh (ICVB)" [35, 36]. As part of this arm, study participants received handwashing stations (bright red water bucket with a tap), and soapy water bottles (1.5-1 plastic bottles where participants could mix detergent and water to make soapy water for handwashing) $[35,36]$. Community health promoters (CHPs) made regular visits to the households to monitor handwashing station usage and deliver promotion messages. Enrollees were also provided with posters depicting three key times for handwashing: after defecation, before food preparation and before eating.

\section{Study design}

This study represents the initial stage of a sequential exploratory study design [37], and incorporated methods from ethnography and cognitive anthropology [38].

The study was conducted in two phases (Fig. 1). For the first phase, the team conducted 7 in-depth interviews and one focus group discussion to elicit an initial list of behavioral antecedents from the community participants. 
Phase 1 Aim: To elicit an intiail list of behavioral antecedent from the community participants

$\cdot 7$ in depth interviews

$\bullet 1$ focus group discussion

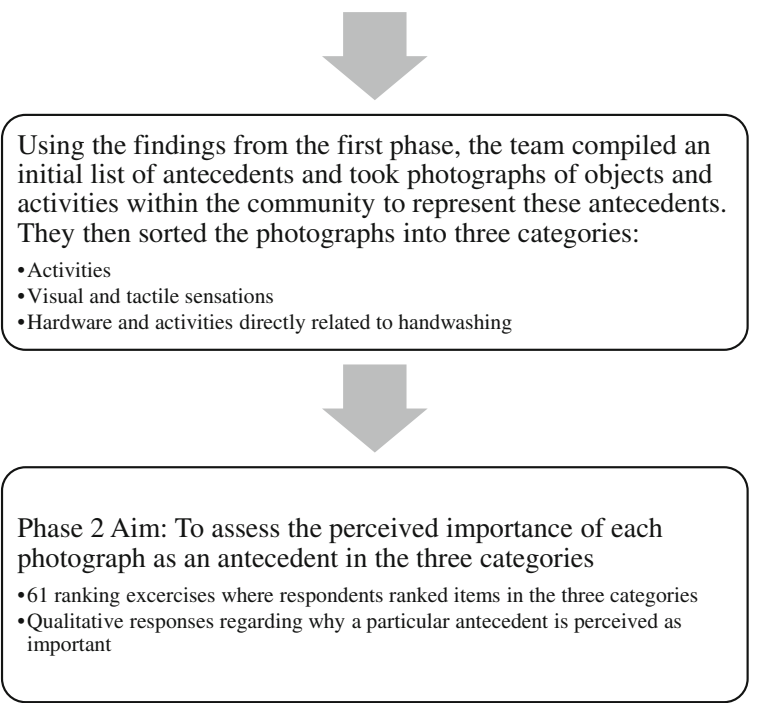

Fig. 1 Flow Diagram of the study data collection phases

Using the findings from the first phase, the team compiled an initial list of antecedents and took photographs of objects and activities within the community to represent these antecedents. They then sorted the photographs, or items from the exhaustive list into three categories:

1. Activities of daily living: coming from the bathroom, before a meal, fish cutting, cleaning a child's anus after defecation, before food preparation, after cleaning dishes, sweeping, brushing hair, coming back from outside, before sleeping at night;

2. Visual or tactile sensations: dirt on hands, sweat, vegetables, handwashing station and soapy water bottle (intervention provided), evening sky, bedsheets, money; and

3. Hardware and activities directly related to handwashing: handwashing station, promotion visit from a CHP, watching someone else wash hands, intervention poster about handwashing, and reminders from a) son or daughter, b) a friend or neighbor, or c) an unknown person to wash hands.

Each of these three categories contained "intervention-related antecedents". These included the three key times that were being promoted as part of the ongoing intervention (coming from the bathroom, cleaning a child's anus after defecation, before food preparation), handwashing station, soapy water bottle, handwashing reminders from posters and community health provider visits.

For phase two, the team showed these photographs to 61 participants and conducted a separate ranking exercise for each category to assess the perceived importance of each photograph as an antecedent.

\section{Sampling and data collection}

The data collection team included first author and research assistants. Five field research assistants in total aided with data collection. Two of the research assistants were trained professionals from icddr,b and three other research assistants were trained by the researcher. The FGD was moderated by one of the trained professionals from icddr,b and the notes were taken by one of the research assistants trained by the researcher.

The sampling in both Phase 1 and Phase 2 was purposive. We relied on the CHPs that were working in the neighborhood as part of the ICVB study to help us gain entrée to the households, to establish rapport with the respondents, and to locate respondents who were willing to participate. Study participants were all females residing in the urban slum who had received the intervention. Men were not available during the day at the time of data collection.

For preparation for the first phase, the data collection team first visited different parts of the study area for two weeks and took notes to identify features of the environment and objects and activities to help develop probes for the qualitative interviews. Once the interview guidelines were finalized, data collection for the first phase commenced.

As part of the all in-depth interviews and the focus group discussion, within the first phase, the data collection team asked about daily activities, and probed about activities and objects in participants' daily lives that influence them to move toward handwashing facilities. The main aim was to identify and note the specific antecedent. For example, within a discussion of daily routine, if there was mention of coming back from outside and freshening up, the interviewer noted down "coming back from outside" as an antecedent.

Antecedents detected were photographed and used for the ranking exercises. For the second phase, photographs representing antecedents were shown to the participants during the separate ranking exercises for each category, to get a sense of what influenced handwashing behavior. For each of the exercises, we laid the photographs in front of the participant and asked them to identify which photograph represented an antecedent that most influenced them to wash hands and then asked them to order remaining photos all the way through to least influential from most influential. Additionally, for each ranking exercise, we also took detailed notes of their verbal reactions and probed 
about their perceptions regarding how and why that particular photograph influences handwashing behavior.

All interviews were conducted in Bengali. The qualitative responses were also noted in Bengali, and later translated to English.

Throughout this study, we asked the participants about what makes them develop the intention to wash hands with water and with or without soap. Even though soap is optimal for disease prevention, and it is known that the sight of soap can remind people to wash their hands, we wanted to elicit a full list of handwashing antecedents other than just soap. We did not probe on handwashing with soap in this initial exploratory study unless the participant mentioned it without prompting.

\section{Sample size}

Since this was a small, pilot study conducted for the purposes of hypothesis generation, and we had limitations in personnel and budget, we did not attempt to make population level inferences. For phase one, we focused on generating, from the study participants, terms and definitions applicable in this social and cultural setting; we were not interested in assessing individual opinions or perspectives at this stage. Cultural Consensus Theory, as described by Romney et al. (1986) [39] provides a statistical justification for small sample sizes (4-10 respondents) when the researcher is examining forms of cultural knowledge with high inter-respondent agreement such as the names of the days of the week. We conducted the first round of interviews with 7 people, based in part on a limited time and personnel during the initial phase of the study.

We conducted one single focus group as a quick check, to determine if any of the terms or antecedents mentioned in the individual interviews were specific to individuals, or idiosyncratic.

In Phase 2, we were no longer interested in eliciting terms for antecedents, but rather in exploring the relative importance of the different antecedents from the perspective of the respondents, and the reasons for their ratings of importance. We anticipated that individual characteristics such as age, level of education, occupation and type of housing might affect the importance of different antecedents, but we did not design the study as a formal assessment of the influence of individual characteristics on ratings of importance. Cultural Consensus Theory suggests that at least 30 respondents are needed when the anticipated average cultural competence is below 0.5. We doubled this to give a sample size of 60 as we anticipated that there might be considerable variation. We ended up interviewing 61 persons.

\section{Data analysis}

For the first phase of data collection, the team maintained a list of antecedents. After each interview, and then focus group discussion, the team members would add to the list based on the notes from that interview. The team would hold discussions among themselves to identify what would count as an antecedent, and because we kept our criteria very broad, we incorporated activities such as coming back from outside, or evening sky.

For the second phase of data collection, we collected quantitative and qualitative data.

The quantitative rankings are reported as mean ranks. We averaged the ranking for each photograph and calculated the standard deviations for each rank. We also calculated standard deviations as an indicator of agreement, or high consensus, among participants.

The ranking exercise data were interpreted through the lens of prototype theory. Prototype Theory (graded categorization) was first described in the 1970s [40]. As per this theory, if we ask people about when and where they wash hands, they will first mention more prototypical situations for handwashing, the conventional and accepted occasions for handwashing. People may not mention, or be aware of less prototypical situations where they wash hands. However, the less prototypical items may play important roles in making handwashing behavior habitual. It is possible that these less prototypical items ranked lower, but are still important for further exploration. This is why, we used additional criteria, in addition to high rank and low standard deviation, to identify antecedents that warrant further investigation. These criteria are explained in the Discussion section.

Our interpretations of the quantitative ranking data were informed by complementary qualitative data. We summarized the reasons for the ranking of each type of antecedent examined in the exercise. We then compiled the qualitative responses of all participants. For example, for sweat, we listed everything that all respondents mentioned about sweat and why they felt that sweat is an important antecedent. Then we looked for patterns of similarities and differences regarding why a participant perceived an antecedent to be effective.

\section{Results}

Most participants were within the age range of 20-40 years and had no education or education till class 5 (Table 1 ). After coming out of the bathroom and dirt (moyla) on hands were the two antecedents that ranked highest in two of the ranking categories (activities of daily living identified as antecedents and visual and tactile sensations identified as antecedents). They also had lower standard deviations, indicating higher consensus about their ranking. Ranking was less consistent for the category for hardware and activities directly related to handwashing (Table 2).

Intervention items ranked higher than the nonintervention items; however the standard deviations were high across all items, possibly indicating lower consensus on the rankings. The qualitative responses provided context 
Table 1 Demographic information for ranking exercise participants $(N=61)$

\begin{tabular}{ll}
\hline Characteristics & Total $(N=61)$ \\
\hline Participants' age (years) & 5 \\
Less than 20 & 22 \\
20 to 29 & 18 \\
30 to 39 & 12 \\
40 to 49 & 4 \\
50 and more & \\
Participants' education & 28 \\
No education & 14 \\
Till Class 5 & 19 \\
More than Class 5 & 16 \\
Monthly Income in Bangladeshi taka (USD) & 33 \\
1500 to 5000 (10 to 63) & 8 \\
5500 to 10,000 (69 to 125) & 4 \\
10,500 to 15,000 (131 to 188) & \\
Above 15,500 (above 194) &
\end{tabular}

and explanations for why different participants seemed to value different antecedents.

\section{Activities of daily living identified as antecedents}

Coming out of the bathroom was consistently ranked highly by participants, and was connected to comments on germs, smell and fear of sickness. One participant mentioned that it is natural and too obvious to warrant further explanation.
"After coming out of bathroom, maybe I will eat something and germs will get into my stomach. So I wash to stop that"

"There are germs in the bathroom and the hands smell" "This is most important, because right after waking up in the morning, first thing I do is go to bathroom and then I wash hands"

Handwashing before a meal ranked second in the list. In Bangladesh the practice is to eat with hands so participants described the need to wash hands prior to eating as an obvious time, and that it was a habit or obbhyash to do so in order to remove dirt (moyla) and sicknesses. The word "moyla" in Bengali refers to dust and dirt, and more broadly to anything containing germs, or any kind of dirtiness. It can be translated as dirt, grime, soil or filth.

"I always have to do this. It's obvious"

"There might be dirt (moyla) in the nails, so we will wash hands till hands are clean and then we will sit down to eat"

"The food won't be contaminated and sicknesses won't enter my stomach"

When it came to cutting raw fish before cooking, respondents cited the accompanying greasy sensation and smell that remained on hands compelled them to wash their hands.

"Fish can make hands smell and then there is a disgusting smell when I go to eat something. The smell is stuck to my hands"

Table 2 Mean Ranks for Antecedents

\begin{tabular}{|c|c|c|c|c|c|c|}
\hline \multirow[t]{2}{*}{ Rank } & \multicolumn{2}{|c|}{ Activities identified as antecedents } & \multicolumn{2}{|c|}{$\begin{array}{l}\text { Visual or Tactile sensations } \\
\text { identified as antecedents }\end{array}$} & \multicolumn{2}{|l|}{$\begin{array}{l}\text { Hardware and activities } \\
\text { directly related to handwashing }\end{array}$} \\
\hline & Description & Mean Rank (SD) & Description & Mean Rank (SD) & Description & Mean Rank (SD) \\
\hline 1 & $\begin{array}{l}\text { Coming out of } \\
\text { bathroom }\end{array}$ & $1.13(0.74)$ & Dirt on Hands & $1.31(0.92)$ & Handwashing Station & $2.72(1.86)$ \\
\hline 2 & Before Meal & $3.07(1.57)$ & Sweat & $3.56(1.61)$ & Community Health Providers & $3.26(1.91)$ \\
\hline 3 & Fish Cutting & $4.21(1.44)$ & Vegetables & $3.75(1.77)$ & Reminder from Son or Daughter & $3.48(1.62)$ \\
\hline 4 & $\begin{array}{l}\text { Cleaning Child's anus } \\
\text { after defecation }\end{array}$ & $4.79(2.86)$ & Handwashing Station & $3.93(1.81)$ & Watching someone else wash hands & $3.85(1.67)$ \\
\hline 5 & Before Food Preparation & $4.87(2.03)$ & Soapy Water Bottle & $4.95(1.54)$ & Reminder from Poster & $3.97(1.95)$ \\
\hline 6 & After Cleaning Dishes & $5.59(1.94)$ & Evening Sky & $5.23(1.60)$ & Reminder from Friend or Neighbor & $4.43(1.54)$ \\
\hline 7 & Sweeping & $7.30(1.98)$ & Bedsheet & $6.16(1.72)$ & Reminder from an unknown person & $6.31(1.31)$ \\
\hline 8 & Brushing Hair & $7.44(1.67)$ & Money & $7.13(1.60)$ & & \\
\hline 9 & $\begin{array}{l}\text { Coming Back From } \\
\text { Outside }\end{array}$ & $7.61(1.43)$ & & & & \\
\hline 10 & $\begin{array}{l}\text { Before Sleeping At } \\
\text { Night }\end{array}$ & $8.98(1.40)$ & & & & \\
\hline
\end{tabular}


Cleaning a child's anus after defecation was the fourth most common activity antecedent, connected by study participants to factors affecting illness occurrence and prevention, such as the desire to maintain children's health and reduce exposure to germs and illness.

When we showed pictures of a woman in the kitchen preparing food, and asked whether they would wash hands before food preparation, participants mentioned that they might wash hands after food preparation, and not necessarily before. Specifically, they mentioned that handling vegetables, fish and spices during food preparation will compel them to wash hands.

The bottom five ranking antecedents included washing dishes, sweeping, brushing hair, coming back from outside, and before sleeping at night. Among these, washing dishes and brushing hair elicited inconsistent responses regarding their importance as triggers to handwashing. While some participants said that the hands get washed in the process of cleaning dishes, others highlighted that the process of cleaning dishes can result in oil or fat from the leftover food and the kali or black burnt-on or scorch stains from the bottom of pots transferring to hands. Similarly, for hair brushing, some participants said that it is not necessary to wash hands after brushing hair, but some connected this activity with coming into contact with lice and oil which led them to wash hands. Bangladeshi women commonly apply coconut oil to their hair, and the odor of coconut oil is distinct.

\section{"I feel disgusted after touching hair. Because we kill lice} after putting oil in hair that is why I wash my hands"

\section{"If I brush hair, oil will get on hands from the hair oil} in our hair. So I wash hands"

Sweeping and coming back from outside were themes that were connected with evening time, dust, dirt and the need to freshen up. Some said that the sight of the tap and soap after coming back from outside will trigger the need to wash hands.

"In the evening I will also sweep and if there is too much moyla then I will wash"

Most participants said that they do not routinely wash hands before going to bed at night, but those who did, mentioned that it is a habit and that they like freshening up before going to sleep.

\section{Visual or tactile sensations identified as antecedents}

Dirt (moyla) on hands was described by all study participants as a very strong antecedent for handwashing.

"Everyone will wash hands when the hands are dirty and have moyla. I feel disgusted if there is moyla on hands. Also we wash hands to avoid diarrhea" "hands feel disgusting when moyla gets there"

Wiping sweat from forehead came up as a strong antecedent for handwashing. Participants explained that sweat prompted them to wash their hands because sweat results in itching, it is sticky and salty and it gives off a bad smell. Participants claimed they felt the need to clean up after wiping sweat.

We showed a picture of a woman holding vegetables in the market. Some participants interpreted this picture as "after cutting vegetables" as opposed to touching vegetables. Some mentioned that they will wash hands after cutting vegetables.

Participants spoke favorably of the intervention hardware, the handwashing station and soapy water bottle, that acted as visual antecedents. They found the red colored handwashing station attractive to look at and the placement of handwashing stations increased convenience. The soapy water bottle was kept as part of the handwashing station and so it also ranked highly. Participants mentioned that the soapy water was convenient because it was mixed and ready for use.

Participants connected evening with time for prayer, finishing household work and asking children to freshen up and start studying. Participants also explained how evening is the time when they come back from outside and there is a need to freshen up, because one was exposed to dust and dirt from the streets outside.

"The streets have dust and dirt that get into the body"

"As soon as the call to prayer happens, I will perform ablution with water and then pray. I always do this"

"In the evening I will freshen up and freshen my

children and wash their hands and feet and send them to study"

"This is also important. At evening I finish my cooking, finish working, I have to wash my hands and feet then

Items such as pictures of hands touching bedsheets or money ranked consistently low overall, and most participants said that it is not necessary to wash hands after touching bedsheets or money, even though they were mentioned in the first round of interviews.

\section{Hardware and activities directly related to handwashing}

This exercise involved ranking candidate reminders for people to wash hands from posters, home visits by CHPs and other reminders.

In the qualitative responses, participants continued to speak favorably regarding the intervention hardware and promotional activities. Most participants mentioned that the handwashing station acts as a strong reminder for washing hands in addition to reminders from children and CHPs. 
"Since we come from an uneducated environment, the CHPs are teaching us and that encourages us"

"The neighbors will not be around always, they will come and go, but my daughter will always be inside the house and so she reminds us the most"

"Children study so they know"

Participants spoke favorably of the posters, however some mentioned that they did not like hanging the posters in their homes. During our observations, we also found that many had put away the posters inside drawers. One participant mentioned a religious injunction against hanging such posters near where one performs ablutions and prays.

"For Islamic prayer ritual, I turn it around, but there are some next to the (handwashing) station, so those remind me to wash hands"

Watching someone else wash hands, reminders from friends and neighbors, and unknown persons elicited mixed responses. Some mentioned that this can be a good motivator, but most explained how they are the ones reminding others and some became defensive and mentioned that they do not need others reminding them.

"Yes I tell my neighbors. I tell them that the

handwashing station has been given to you just to keep for show? You should wash hands. You can learn well because of this"

"I hear in it one ear and take it out from the other ear "meaning "I don't pay attention or importance to them" "Their business is their business and mine is mine. I don't pay attention to what they are doing"

\section{Discussion}

The current study identified two existing antecedents that were unanimously perceived as prototypical for handwashing - coming out of the bathroom and dirt or moyla on hands. In addition, the current study identified a host of other antecedents that ranked lower and were less prototypical but may still represent antecedents that can be useful for future handwashing promotion.

Prototype theory suggests that people may assign a high ranking to an item in a category because it has prototypical characteristics, not necessarily because it is important or influential [40]. Based on this premise, we took into account several other criteria beyond the results of the ranking exercise to define a set of antecedents that warrant further exploration in future studies.

We were expecting intervention-related antecedents to rank relatively higher than non-intervention antecedents (since the intervention antecedents were being promoted actively in this community) but this was not strictly the case. Even though participants spoke favorably of the intervention antecedents in qualitative responses, perhaps a result of courtesy or novelty biases, intervention items did not consistently rank higher than non-intervention items in the ranking exercises. This is why we first considered antecedents that ranked higher than the lowest ranking intervention antecedent that were actively promoted in the intervention activities. Items that ranked higher than the lowest intervention items may warrant further consideration since they were likely competing with antecedents that were being promoted actively in this community. For example, in the case of the first category, the intervention-related antecedent that ranked the lowest was food preparation which ranked at 5 . Before meal and fish cutting were the two antecedents that were not related to the intervention that ranked higher than the food preparation, so we took these into consideration.

We secondly considered antecedents for which the qualitative responses highlighted certain nuances in interpretation that must have affected the ranking decisions deeming the corresponding rank as inconclusive. We thirdly considered antecedents that came up as relevant repeatedly in connection to qualitative responses to other antecedents.

\section{Potential handwashing antecedents for future handwashing promotion}

As per our first criterion for identifying potentially important antecedents, cutting fish, before meals, dirt on hands, sweat and vegetables, reminder from son or daughter, and watching someone else wash hands are worth considering in future handwashing promotional activities. Cutting fish, dirt on hands, sweat and vegetables are antecedents that were connected by respondents with the sensory feeling of disgust. The relationship between disgust and handwashing has been identified to be both strong and universal $[26,41]$ and possibly having an evolutionary basis [27]. For handwashing promotion, disgust has conventionally been linked with feces. However, participants in the current study rarely mentioned feces as a handwashing antecedent, despite its prominence in the handwashing promotion literature. Washing hands before a meal (an antecedent connected with the habit and cultural practice of eating with hands), reminder from son and daughter and watching someone else wash hands are non-disgust antecedents that can also be considered for further promotion.

As per our second criterion, for some of the antecedents, the qualitative responses highlighted how nuances in interpretation of the photo images might have affected the rankings. For example, participants mentioned that simply brushing hair by itself does not compel one to wash hands, but many connected brushing hair with hair oil and lice on hands which were cited as good reasons for washing hands. Cleaning dishes, similarly, was equated with leaving oil, fat 
and scorch marks or kali from the pans on hands. We know that disgust is an important motivator for handwashing [28] and therefore, oil, fat and kali stuck to dishes, and oil and lice from hair seem to be important disgust-related antecedents for washing hands (even though brushing hair and after cleaning dishes ranked low) that warrant further exploration.

As per our third criterion, one particular antecedent, evening sky or observing the sunset, was frequently linked with other antecedents (and when asked about other antecedents, they were frequently linked with evening sky). Evening time is marked by the call to prayer, and was linked with coming back from outside where there is exposure to dust and dirt while walking or working. Evening sky and coming back from outside were both linked to the sight of the tap on entering the house. Evening further marks the time of day to finish household chores such as cooking, sweeping the house, and asking children to freshen up, all of which contribute to adults' need to freshen up. It seems that during the evening, a confluence of different antecedents may work together to increase the likelihood of washing hands, so framing handwashing promotion messages around evening time may be more effective than solely focusing on high risk times [24].

\section{Study limitations}

The current study has associated limitations. First, psychologists emphasize that a large proportion of our triggers are unconscious. Handwashing interventions try to inculcate the behavior to the extent that it becomes a habit practiced with a high degree of automaticity [42]. We were able to obtain information only on antecedents that participants easily recalled from their own experiences; habitual behavior is less often easily recalled. To obtain antecedents that may not be so obvious or that respondents might not be conscious of, the study team probed participants extensively in the first round of interviews to obtain a list that was as exhaustive as possible. The first round of interviews stopped only when data saturation was reached and participants were no longer mentioning new antecedents.

A second limitation is that researchers have noted that participants may choose to respond to questions in an interview based on what they perceive the interviewer wants to hear, a phenomenon often referred to as courtesy bias $[43,44]$. In this study, study participants may have perceived that the study team wanted to hear that they washed hands during the key times promoted by the intervention and because of the hardware provided by the intervention. It is possible that they assumed the study team was less interested in other times or places that preceded handwashing. This is a difficult bias to adequately address. However, using a ranking method, we obtained some antecedents that were not intervention related that were identified as important by the community, and these antecedents might be important for future consideration.
A third limitation is that the behavioral antecedents identified in this community may be quite different to behavioral antecedents in other communities. To address this concern, future studies can similarly elicit such lists which will differ from one context to another. A fourth limitation is that the current study provides data only on women, primarily because, handwashing interventions are aimed at caregivers. Young children and infants have developing immune systems and attacks to their immune systems can lead to irreversible growth faltering, which is why caregiver's hand hygiene is particularly important to prevent growth faltering in children. However, future studies should elicit similar lists for men, so that handwashing interventions can include them also.

A final limitation is that the current study did not focus on washing hands with soap, but instead, focused on what compels someone to form the intention to wash hands, even if using water only. Antecedents to rinsing hands with water, with or without soap, are relevant antecedents for the general practice of handwashing which with behavioral coaching or support could include soap.

Despite these concerns, this study makes a valuable contribution to the literature, because it has identified a larger set of antecedents to be investigated and tested in future research on how to most effectively promote regular handwashing with soap.

\section{Strategies for promoting handwashing}

These newly recognized antecedents can be used in strategies for handwashing promotion. Our study found that people hide posters out of religious concerns. Some consider pictures of human figures as unreligious. In such cases, intervention materials might replace human figures with pictures of more relatable antecedents identified as part of the current research to elicit disgust (oil and fat and kali from dishes, oil and lice in hair, smell of fish, moyla on hands, sweat and cutting vegetables). Posters could be fixed at the entrance to the kitchen and say "you are now entering food preparation area..." with pictures of relatable antecedents to remind people that entering the kitchen means that they need to wash hands.

A further strategy can be to draw analogies $[45,46]$. Promoters can link "community key times" to "study key times." For example, CHPs can say "Of course, everyone washes their hands after touching fish, after getting oil and lice on their hands, but other important times to wash hands are before food preparation....". Here, touching fish and getting lice or oil on hands are the naturally occurring antecedents that we seek to link to the key times for handwashing such as before food preparation [24]. Furthermore, evening marks a temporal threshold that can be utilized as a reminder in an intervention. For example, posters can read "Just as you wash your hands after coming home in the evening, so too you need to wash your hands in the morning and in the 
afternoon before preparing meals" and "the call to prayer in the evening is a good reminder to freshen up, similarly, the time before preparing food in the mornings or afternoons is a good reminder to wash hands.".

\section{Conclusions}

Efforts to encourage handwashing at key times which have been promoted for the last two decades have not resulted in high levels of handwashing with soap [25, 47, 48]. Alternatively, adopting a strategy to highlight existing antecedents that people themselves have identified as important can help devise an intervention that is more relatable and effective. Future programs can use these new antecedents to design, pilot and test behavior change messages and promotional strategies to increase handwashing as a way to have hands cleaned more frequently during the day. Even if handwashing does not occur at key times, an overall increase in handwashing frequency may improve health.

\section{Acknowledgements}

The first author would like to acknowledge the intellectual contributions of Dr. Abbas Uddin Bhuiya (Deputy Executive Director, icddr,b) and Dr. Robert Dreibelbis (Assistant Professor, London School of Hygiene and Tropical Medicine) during the design of the study protocol.

\section{Funding}

The data collection of the current study was funded by the James P. Grant School of Public Health, BRAC University. The manuscript development process was supported by the Environmental Interventions Unit (EIU), Infectious Diseases Division (IDD) at icddr,b. icddr,b is grateful to the government of Bangladesh, Canada, Sweden and the UK for providing core/unrestricted support.

\section{Availability of data and materials}

The datasets that were created and analyzed as part of the current study are available from the corresponding author on reasonable request.

\section{Authors' contributions \\ MJR designed, collected, analyzed and interpreted data and wrote the manuscript. PJW contributed as senior author, guiding MJR with the conception, design and writing up of the findings. FAN assisted with design data collection and writing of manuscript. LU and SL contributed to data analysis by drafting the work and revising it critically for important intellectual content. All authors read and approved the final manuscript.}

\section{Competing interests}

The authors declare that they have no competing interests.

\section{Consent for publication}

The manuscript does not contain details of any individual participant. We used photos of residents from within the community to create the antecedent photographs, and we had taken consent from the community to use those photographs for data collection purposes. However, we did not obtain consent for use of those photographs beyond data collection. Since the photographs used for antecedents contain recognizable individual faces, we are unable to share these photographs.

\section{Ethics approval and consent to participate}

The research team stated the research study objectives clearly to the participants. Before taking part in the study, participants provided written informed consent. The first author was an MPH student at the James P. Grant School of Public Health in Dhaka at the time of this study. The study protocol therefore was reviewed by, and received approval from, the James P. Grant School of Public Health, BRAC University's Ethical Review Committee.

\section{Publisher's Note}

Springer Nature remains neutral with regard to jurisdictional claims in published maps and institutional affiliations.

\section{Author details}

${ }^{1}$ International Center for Diarrheal Diseases Research, Bangladesh (icddr,b), Dhaka, Bangladesh. ${ }^{2}$ Division of Infectious Diseases and Geographic Medicine, Stanford University, Stanford, CA, USA. ${ }^{3}$ Social and Behavioral Interventions (SBI) Program, Department of International Health, Johns Hopkins Bloomberg School of Public Health, Baltimore, MD, USA.

Received: 28 July 2016 Accepted: 26 April 2017

Published online: 05 May 2017

\section{References}

1. Walker CLF, Rudan I, Liu L, Nair H, Theodoratou E, Bhutta ZA, O'Brien KL, Campbell H, Black RE. Global burden of childhood pneumonia and diarrhoea. Lancet. 2013;381(9875):1405-16.

2. Liu L, Li Q, Lee RA, Friberg IK, Perin J, Walker N, Black RE. Trends in causes of death among children under 5 in Bangladesh, 1993-2004: an exercise applying a standardized computer algorithm to assign causes of death using verbal autopsy data. Popul Health Metrics. 2011;9(1):1.

3. Ejemot-Nwadiaro RI, Ehiri JE, Meremikwu MM, Critchley JA. Hand washing for preventing diarrhoea. The Cochrane Library. 2008;

4. Rabie T, Curtis V. Handwashing and risk of respiratory infections: a quantitative systematic review. Tropical Med Int Health. 2006;11(3):258-67.

5. Aiello AE, Coulborn RM, Perez V, Larson EL. Effect of hand hygiene on infectious disease risk in the community setting: a meta-analysis. Am Public Health. 2008;98(8):1372-81.

6. Cairncross S, Hunt C, Boisson S, Bostoen K, Curtis V, Fung IC, Schmidt W-P. Water, sanitation and hygiene for the prevention of diarrhoea. Int $J$ Epidemiol. 2010;39(suppl 1):i193-205.

7. Tappero JW, Tauxe RV. Lessons learned during public health response to cholera epidemic in Haiti and the Dominican Republic. Emerg Infect Dis. 2011;17(11):2087-93

8. Mahamud AS, Ahmed JA, Nyoka R, Auko E, Kahi V, Ndirangu J, Nguhi M, Burton JW, Muhindo BZ, Breiman RF. Epidemic cholera in Kakuma refugee camp, Kenya, 2009: the importance of sanitation and soap. The Journal of Infection in Developing Countries. 2011;6(03):234-41.

9. Vergnano S, Sharland M, Kazembe P, Mwansambo C, Heath P. Neonatal sepsis: an international perspective. Arch Dis Child Fetal Neonatal Ed. 2005; 90(3):F220-FF4.

10. Edmond K, Zaidi A. New approaches to preventing, diagnosing, and treating neonatal sepsis. PLoS Med. 2010;7(3):e1000213.

11. van Dillen J, Zwart J, Schutte J, van Roosmalen J. Maternal sepsis: epidemiology, etiology and outcome. Curr Opin Infect Dis. 2010;23(3):249-54

12. Aledort JE, Lurie N, Wasserman J, Bozzette SA. Non-pharmaceutical public health interventions for pandemic influenza: an evaluation of the evidence base. BMC Public Health. 2007:7(1):208.

13. Freeman MC, Stocks ME, Cumming O, Jeandron A, Higgins J, Wolf J, Prüss-Ustün A, Bonjour S, Hunter PR, Fewtrell L. Systematic review: hygiene and health: systematic review of handwashing practices worldwide and update of health effects. Tropical Med Int Health. 2014; 19(8):906-16.

14. Luby SP, Agboatwalla M, Bowen A, Kenah E, Sharker Y, Hoekstra RM. Difficulties in maintaining improved handwashing behavior, Karachi, Pakistan. AmJTrop Med Hyg. 2009:81(1):140-5.

15. Curtis VA, Danquah LO, Aunger RV. Planned, motivated and habitual hygiene behaviour: an eleven country review. Health Educ Res. 2009:24(4):655-73

16. Fewtrell L, Kaufmann RB, Kay D, Enanoria W, Haller L, Colford JM. Water, sanitation, and hygiene interventions to reduce diarrhoea in less developed countries: a systematic review and meta-analysis. Lancet Infect Dis. 2005 5(1):42-52.

17. Aunger R, Schmidt W-P, Ranpura A, Coombes Y, Maina PM, Matiko CN, Curtis $\mathrm{V}$. Three kinds of psychological determinants for hand-washing behaviour in Kenya. Soc Sci Med. 2010;70(3):383-91.

18. Bandura A. Self-efficacy: toward a unifying theory of behavioral change. Psychol Rev. 1977;84(2):191. 
19. Curtis V, Schmidt W, Luby S, Florez R, Touré O, Biran A. Hygiene: new hopes, new horizons. Lancet Infect Dis. 2011;11(4):312-21.

20. Ford EW, Boyer BT, Menachemi N, Huerta TR. Increasing hand washing compliance with a simple visual cue. Am J Public Health. 2014;104(10): 1851-6.

21. Devine J. Beyond tippy-taps: the role of enabling products in scaling up and sustaining handwashing. Waterlines. 2010;29(4):304-14.

22. Baer DM, Wolf MM, Risley TR. Some current dimensions of applied behavior analysis1. J Appl Behav Anal. 1968;1(1):91-7.

23. Lehman PK, Geller ES. Behavior analysis and environmental protection: accomplishments and potential for more. Behavior and social issues. 2004;13(1):13.

24. Luby SP, Halder AK, Huda T, Unicomb L, Johnston RB. The effect of handwashing at recommended times with water alone and with soap on child diarrhea in rural Bangladesh: an observational study. PLoS Med. 2011; 8(6):e1001052

25. Nizame FA, Nasreen S, Halder AK, Arman S, Winch PJ, Unicomb L, Luby SP. Observed practices and perceived advantages of different hand cleansing agents in rural Bangladesh: ash, soil, and soap. AmJTrop Med Hyg. 2015;92(6):1111-6.

26. Curtis V. Talking dirty: how to save a million lives. Int J Environ Health Res. 2003, 13(sup1):S73-S9.

27. Curtis V, Aunger R, Rabie T. Evidence that disgust evolved to protect from risk of disease. Proc R Soc Lond B Biol Sci. 2004;271(Suppl 4): S131-S3.

28. Curtis V. Why disgust matters. Phil Trans R Soc B. 2011;366(1583):3478-90.

29. Curtis V, de Barra M, Aunger R. Disgust as an adaptive system for disease avoidance behaviour. Philosophical Transactions of the Royal Society of London B: Biological Sciences. 2011;366(1563):389-401.

30. Biran A, Schmidt W-P, Varadharajan KS, Rajaraman D, Kumar R, Greenland K, Gopalan B, Aunger R, Curtis V. Effect of a behaviour-change intervention on handwashing with soap in India (SuperAmma): a cluster-randomised trial. Lancet Glob Health. 2014;2(3):e145-e54.

31. Scott BE, Schmidt WP, Aunger R, Garbrah-Aidoo N, Animashaun R. Marketing hygiene behaviours: the impact of different communication channels on reported handwashing behaviour of women in Ghana. Health Educ Res. 2008;23(3):392-401.

32. Curtis V, Kanki B, Cousens S, Diallo I, Kpozehouen A, Sangare M, Nikiema M. Evidence of behaviour change following a hygiene promotion programme in Burkina Faso. Bull World Health Organ. 2001;79(6):518-27.

33. Winch PJ, Thomas ED. Harnessing the power of emotional drivers to promote behaviour change. Lancet Glob Health. 2016;4(12):e881-e2.

34. Judah G, Aunger R, Schmidt W-P, Michie S, Granger S, Curtis V. Experimental pretesting of hand-washing interventions in a natural setting. Am J Public Health. 2009;99(S2):S405-S11.

35. Uddin MJ, Wahed T, Saha NC, Kaukab SST, Khan IA, Khan Al, Saha A, Chowdhury F, Clemens JD, Qadri F. Coverage and acceptability of cholera vaccine among high-risk population of urban Dhaka. Bangladesh Vaccine. 2014;32(43):5690-5.

36. Qadri F, Ali M, Chowdhury F, Khan Al, Saha A, Khan IA, Begum YA, Bhuiyan TR, Chowdhury MI, Uddin MJ. Feasibility and effectiveness of oral cholera vaccine in an urban endemic setting in Bangladesh: a cluster randomised open-label trial. Lancet. 2015;386(10001):1362-71.

37. Creswell JW Research design: Qualitative, quantitative, and mixed methods approaches. vol.: Sage publications; 2013.

38. Bernard HR Research methods in anthropology: Qualitative and quantitative approaches. vol.: Rowman Altamira; 2011.

39. Romney AK, Weller SC, Batchelder WH. Culture as consensus: a theory of culture and informant accuracy. Amer Anthrop. 1986;88(2):313-38.

40. Rosch E. Cognitive representations of semantic categories. J Exp Psychol Gen. 1975;104(3):192

41. Curtis V. Hygiene: how myths, monsters, and mothers-in-law can promote behaviour change. J Inf Secur. 2001;43(1):75-9.

42. Wood W, Quinn JM, Kashy DA. Habits in everyday life: thought, emotion, and action. J Pers Soc Psychol. 2002;83(6):1281.

43. Deutscher I. Asking questions cross-culturally: some problems of linguistic comparability. Comparative research methods. 1973;163:186.

44. Niikura R. Assertiveness among Japanese, Malaysian, Filipino, and US whitecollar workers. J Soc Psychol. 1999:139(6):690-9.

45. van der Geest S Anthropology and international health: South Asian case studies: by Mark Nichter. Kluwer, Dordrecht, 1989. 314 pp. In.: Pergamon; 1993.
46. Whaley B, Stone A, Brady S, Whaley R. Explaining diabetes: studying the effects of using analogies to talk about illness. Journal of Diabetes Nursing 2014;18(2):72-6.

47. Zeitlyn S, Islam F. The use of soap and water in two Bangladeshi communities: implications for the transmission of diarrhea. Rev Infect Dis. 1991, 13(Supplement 4):S259-S64.

48. Baker KK, Farzana FD, Ferdous F, Ahmed S, Das SK, Faruque A, Nasrin D, Kotloff KL, Nataro JP, Kolappaswamy K. Association between moderate-to-severe diarrhea in young children in the global enteric multicenter study (GEMS) and types of handwashing materials used by caretakers in Mirzapur. Bangladesh Am J Trop Med Hyg. 2014;91(1):181-9.

\section{Submit your next manuscript to BioMed Central and we will help you at every step:}

- We accept pre-submission inquiries

- Our selector tool helps you to find the most relevant journal

- We provide round the clock customer support

- Convenient online submission

- Thorough peer review

- Inclusion in PubMed and all major indexing services

- Maximum visibility for your research

Submit your manuscript at www.biomedcentral.com/submit
) Biomed Central 